\title{
PRIMEIRO RELATO DE Francisella noatunensis SUBESPÉCIE ORIENTALIS NO SUL DO BRASIL - RELATO DE CASO
}

[First report of Francisella noatunensis subspecies orientalis in southern of Brazil-Cause Report]

\author{
Adolfo Jatobá ${ }^{*}$, Susane Pahl Klipp², Roberto Hoppe ${ }^{2}$ \\ ${ }^{1}$ Instituto Federal Catarinense (IFC), Campus Araquari, Laboratório de Aquicultura Araquari, Santa Catarina, \\ Brazil. \\ ${ }^{2}$ Fundação Municipal de Desenvolvimento Rural 25 de Julho.
}

RESUMO - O granuloma visceral sistêmica ou franciselose em peixes é causada por Francisella noatunensis subspécie orientalis e $F$. noatunensis subspécie noatunensis. No Brasil, o primeiro surto de franciselose em tilápias do Nilo (Oreochromis niloticus) foi registrado nos invernos de 2012 e 2013, no estado de Minas Gerais. Entretanto, nada foi observado nas demais regiões produtoras. O objetivo neste trabalho foi diagnosticar o agente causador da mortalidade de tilápia do Nilo (Oreochromis niloticus) em uma unidade produtora do estado de Santa Catarina. Durante um surto de mortalidade em setembro de 2015, foram avaliadas 35 tilápias quanto à presença de parasitos, avaliação microbiológica e análise da reação em cadeia da polimerase. Após análises, foi registrada a presença da $F$. noatunensis subespécie orientalis, sendo o primeiro relato no sul do Brasil.

Palavras-Chaves: Santa Catarina; Oreochromis niloticus; tilápia; granuloma visceral.

\begin{abstract}
The systemic visceral granuloma or franciselose is caused by Francisella noatunensis subspecies orientalis and $F$. noatunensis subspecies noatunensis. In Brazil, the first Francisella outbreak of Nile tilapia (Oreochromis niloticus) was recorded in the winters of 2012 and 2013 in the state of Minas Gerais. However, nothing was observed in the other producing regions. The aim of this study was to diagnose the causative agent of mortality Nile tilapia (Oreochromis niloticus) in a production unit in the state of Santa Catarina. For a mortality outbreak in September 2015, we were evaluated 35 Tilapia for the presence of parasites, microbiological evaluation and analysis of the polymerase chain reaction. After analysis, it was registered the presence of $F$. noatunensis subspecies orientalis, the first reported in southern Brazil
\end{abstract}

Keywords: Santa Catarina; Oreochromis niloticus; tilapia; visceral granuloma.

\footnotetext{
* Autor para correspondência. E-mail: adolfo.jatoba@ifc-araquari.edu.br Recebido: 17 de fevereiro de 2016.

Aceito para publicação: 07 de abril de 2016.
} 


\section{INTRODUÇÃO}

O granuloma visceral sistêmico ou franciselose é causada pelo cocobastonete Gram negativo Francisella ssp. Essa bactéria é estritamente aeróbia e apresenta crescimento intracelular facultativa. Esta bacteriose é emergente na aquicultura mundial, podendo causar perdas em ambientes marinhos e dulcícolas (Vestvik et al., 2013; Nguyen et al., 2015). Recentemente foram identificados dois agentes etiológicos Francisella noatunensis subspécie orientalis e $F$. noatunensis subspécie noatunensis que são responsáveis pela bacteriose em águas tropicais e temperadas, respectivamente (Soto et al., 2009; Duodu et al., 2012; Vestvik et al., 2013; Nguyen et al., 2015).

Nas duas últimas décadas, países como Japão, Tailândia, Taiwan, indonésia, Noruega, Suécia, Reino Unido, Estados Unidos, Costa Rica, Chile e Brasil já registraram surtos dessa bactéria (Nguyen et al., 2015). No Brasil, Leal et al. (2014) registraram o primeiro surto de franciselose em alevinos e juvenis de tilápias do Nilo (Oreochromis niloticus) durante os invernos dos anos de 2012 e 2013, no estado de Minas Gerais (sudeste brasileiro). Entretanto, outros casos ainda não foram reportados nas demais regiões produtoras do Brasil. Assim, o objetivo deste trabalho foi diagnosticar o agente causador da mortalidade de tilápia do Nilo (Oreochromis niloticus) em uma unidade produtora em Joinville, Santa Catarina.

\section{RELATO DE CASO}

As tilápias do Nilo (Oreochromis. niloticus) estavam em um tanque escavado com $6.000 \mathrm{~m}^{2} \mathrm{e}$ $1,2 \mathrm{~m}$ de profundidade média. $\mathrm{O}$ tanque era utilizado como lagoa de estabilização (ou sedimentação) pela estação de piscicultura. No mês de setembro de 2015 foi observada mortalidade discreta (aproximadamente 5\%) de tilápias do Nilo, com aumento progressivo ao longo dos dias. Os peixes estavam apáticos, com cor escura nas beiradas do tanque, não apresentando reações a estímulos como oferta de ração.

A avaliação dos peixes foi dividida em três etapas: $1^{\circ}$ análise das variáveis de qualidade de água e parasitológica; $2^{\circ}$ biopsia; e envio de amostras para laboratório autorizado.

Na primeira etapa, depois de verificar que os níveis de oxigênio dissolvido estavam acima de 4,0 mg.L ${ }^{-}$ ${ }^{1}$, quatorze juvenis de tilápia do Nilo (O. niloticus), com peso médio de $392 \pm 59 \mathrm{~g}$, sendo quatro assintomáticos, foram anestesiados em eugenol (1\%) até sessão dos movimentos operculares, e sacrificados por concussão cerebral, sendo registrada intensidade média (Bush et al., 1997) de
20 para Trichodina sp., Monogenea e Piscinoodinium sp. nas brânquias e muco.

Para biopsia, outros cinco juvenis de tilápia do Nilo (O. niloticus) moribundos, com peso médio de 386 \pm 35 g, com brânquias hemorrágicas, deterioradas e em estágio de decomposição; lesão tegumentar; olhos opacos, e nadadeiras descoloridas (Figura 1) foram utilizados para realização de biopsias. Os peixes foram anestesiados em eugenol (1\%) até sessão dos movimentos operculares, e sacrificados por concussão cerebral. Promoveu-se uma incisão ventral, no sentido da nadadeira caudal a cabeça. Os órgãos foram visualizados e registrados, assim como amostras dos rins, sangue, coração e fígado foram maceradas em gral estéril com solução salina estéril a $0,85 \%$ de $\mathrm{NaCl}$ (SSE) na proporção de 1,0 $\mathrm{g}$ de amostra para $1,0 \mathrm{~mL}$. O macerado foi inoculado em placas de petri contendo e Agar sangue (TSA, "triptone soya Agar", HiMedia, Mumbai, Índia com $5 \%$ de sangue de carneiro desfibrinado), e incubadas por $48 \mathrm{~h}$ a $30^{\circ} \mathrm{C}$. Após os procedimentos de isolamento e purificação pelo método de esgotamento, as cepas foram incubadas por $48 \mathrm{~h}$ a $30^{\circ} \mathrm{C}$ em meio de cultura TSB ("triptone soya broth" HiMedia, Mumbai, Índia) e mantidas no cepário.

Depois da realização da biopsia, outras 16 tilápias do Nilo (O. niloticus) moribundas, com peso entre 61 e 407 g e mesmas características descritas acima (Figura 1), foram envidados ao AQUACEN na Universidade Federal de Minas Gerais para exame bacteriológico e reação em cadeia da polímera quantitativa para Francisella noatunensis subespécie orientalis.

$\mathrm{Na}$ análise bacteriológica foram coletadas, assepticamente, amostras do cérebro e rim para inoculação em meio Àgar Sangue, assim como amostras do rim e baço foram inoculadas em Ágar Cistina Coração (TYC, Difco, USA) suplementado com $1 \%$ de hemoglobina bovina. Todas as amostras foram incubadas por $168 \mathrm{~h}$ a $28^{\circ} \mathrm{C}$ (Rydzewski et al., 2015).

As colônias bacterianas foram identificadas com o equipamento Microflex (MALDI Biotyper, Bruker, EUA), que utiliza tecnologia de MALDI-TOF (do inglês, "Matrix-Assisted Laser Desorption Ionization - Time of Flight") para análise do perfil proteômico e identificação dos micro-organismos (Deak et al., 2015).

Das 16 tilápias, amostras de baço, cérebro e rim de cada animal foram coletadas, assepticamente, e agrupadas para extração de DNA e posterior análise da reação em cadeia da polimerase quantitativa (PCRq) para Francisella noatunensis subespécie orientalis (Soto et al., 2010). Após a PCRq, o DNA 
cromossómico bacteriano foi isolado de acordo com o método descrito por Jafar et al. (2009), e identificação molecular foi realizada como em Martinez et al. (2001).

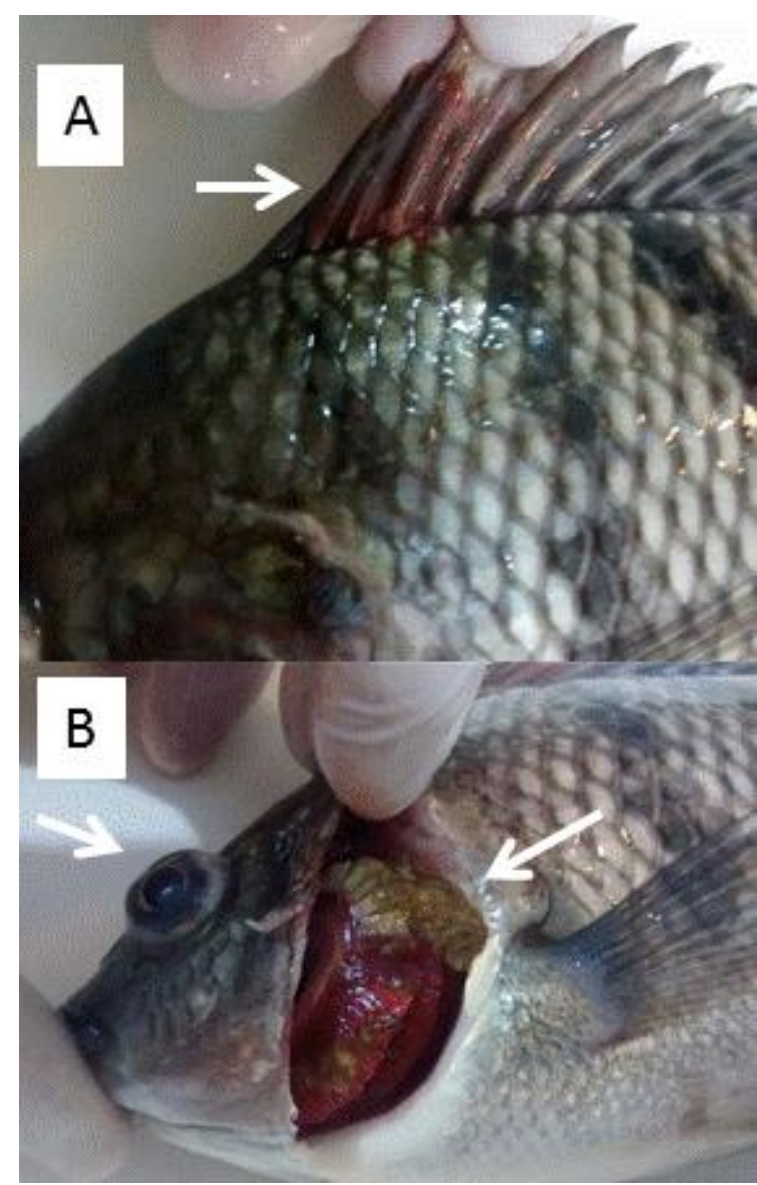

Figura 1. Lesões externas nas nadadeiras (A), olhos opacos (B), e brânquias hemorrágicas (B e C) das tilápias do Nilo (Oreochromis niloticus) selecionadas para biopsia.

\section{DISCUSSÃO}

$\mathrm{Na}$ biopsia dos cinco peixes foi observada a presença de nódulos brancos (granulomas) renais, hepáticos e no coração; tratos intestinais e estômagos vazios, com presença esporádica de líquido amarelo no estômago; rins hipertrofiados; odor desagradável; e fígado esponjoso e com nódulos (Figura 2). Essas alterações já foram reportadas por Birkbeck et al. (2011), Colquhoun \& Duodu (2011) e Nguyen et al. (2015) em peixes contaminados com Francisella ssp.

Os peixes utilizados na biopsia apresentaram ocorrência de $100 \%$ de bactérias hemolíticas nos rins e $50 \%$ de a de bactérias hemolíticas no sangue. No fígado não foi observado presença de bactérias com essas características. A confirmação da
Francisella noatunensis subespécie orientalis foi obtida em setembro de 2015 pelo AQUACEN na Escola de Veterinária da UFMG. Verificou-a ocorrência $62,5 \%$ para esse agente nos 16 juvenis avaliados através do PCR, enquanto nas análises bacteriológicas foi registrada prevalência de 50,0\% para as amostras do baço e $37,5 \%$ do rim, enquanto no cérebro nada foi detectado.

No Brasil, desde 2012 são registradas perdas devido à franciselose em Tilápias do Nilo (O. niloticus) cultivadas em tanque rede, podendo provocar mortalidade de até $60 \%$. Os peixes enfermos apresentam anorexia, melanose, exoftalmia, natação errática, úlceras de pele, brânquias e palidez (Leal et al., 2014). Essas características foram observadas durante o surto em Santa Catarina que registrou mortalidade média de $55 \%$. A falta de registros desta enfermidade, em anos anteriores, pode estar relacionada com a baixa cobertura de técnicos competentes e compromissada com a ética e aquicultura nacional.

Apesar da $F$. noatunensis subespécie orientalis ser característica de clima tropical, ambos os surtos registrados no Brasil (Minas Gerais e Santa Catarina) ocorreram nos períodos em que a água estava mais fria (inverno) que pode ser um "gatilho", fator ambiental necessário (má qualidade de água, manejo inadequado e/ou dieta de baixa qualidade) para este micro-organismo desenvolva sua patogenicidade nos peixes. Essa casuística corrobora com Soto et al. (2012) que ao elevar a temperatura de 25 a $30^{\circ} \mathrm{C}$ preveniu o desenvolvimento de sinais clínicos e mortalidade nos peixes desafiados com $F$. noatunensis. Segundo Soto et al. (2015) esse agente patogênico têm a capacidade de produzir biofilme, além de sobreviver a diferentes salinidades (0 a $35 \%$ ), que dificulta o desenvolvimento de estratégias de prevenção, tratamento e erradicação desse patógeno emergente.

Este cenário ratifica a necessidade do aprimoramento nas técnicas de manejo sanitário, em especial de caráter preventivo, que envolve técnicas simples como: calagem, monitoramento dos parâmetros de qualidade de água e parasitológico, assepsia dos materiais utilizados nos tanques e melhor fluxo de pessoas; a técnicas mais sofisticadas como aplicação de vacinas, probióticos e aditivos alimentares. Este manejo preventivo associado à criação de uma rede eficiente no diagnóstico de doenças nos animais de origem aquática poderia fornecer maiores subsídios aos piscicultores, evitando perdas, e principalmente, reduzindo a disseminação dos agentes patogênicos em meio aquático. 


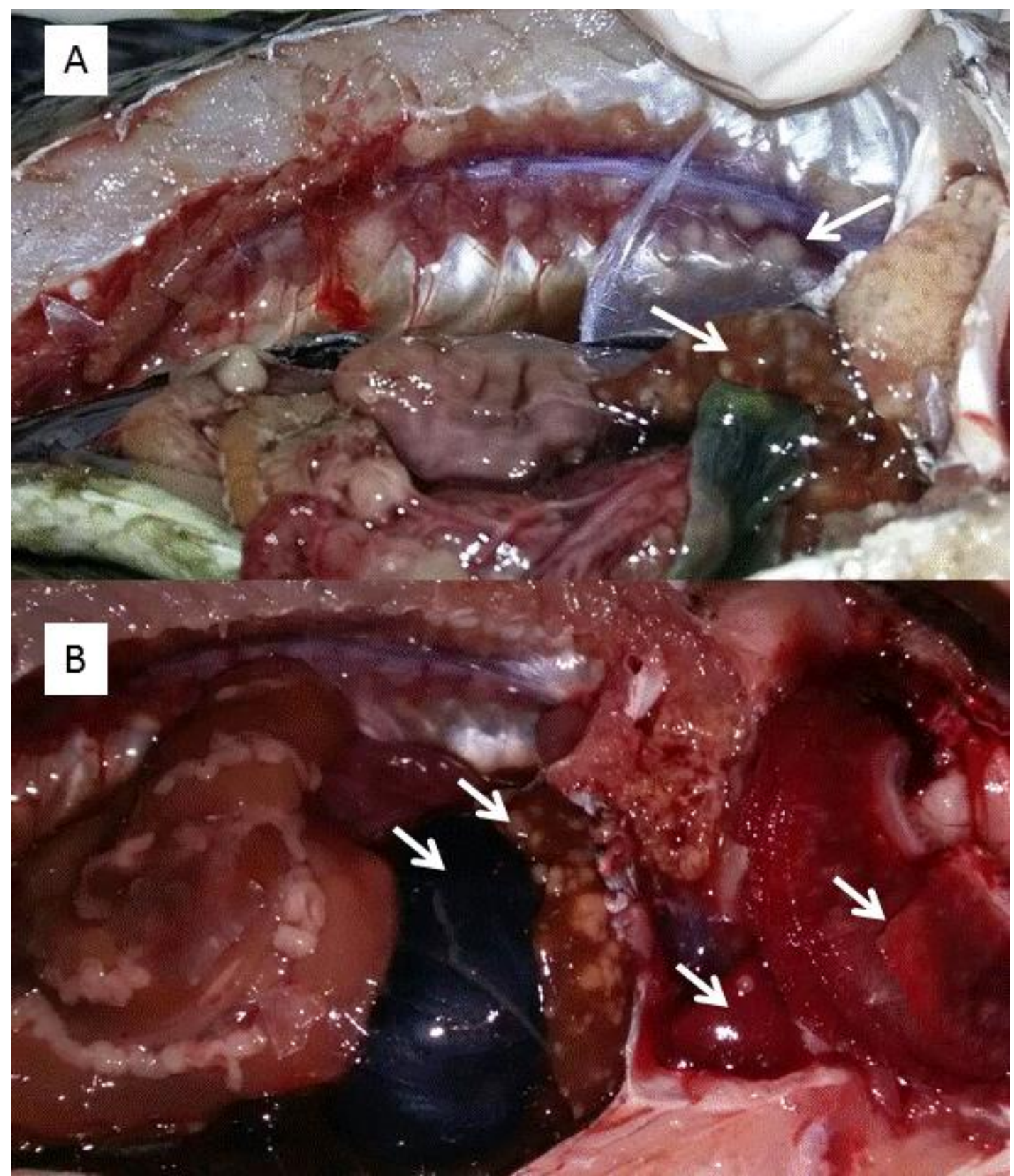

Figura 2. Presença de nódulos brancos no rim e fígado (A), vesícula biliar dilatado, nódulo no coração e brânquias lesionadas das tilápias do Nilo (Oreochromis niloticus) selecionadas para biopsia.

\section{CONCLUSÃO}

A mortalidade das tilápias do Nilo foi ocasionada por Francisella noatunensis subespécie orientalis. Este é o primeiro relato deste patógeno emergente no sul do Brasil, fato que deve ser divulgado aos piscicultores, pois devido as grandes oscilações de temperatura observadas da região, assim como invernos mais rigorosos, torna os peixes susceptíveis ao desenvolvimento dessa bactéria.

\section{REFERÊNCIAS}

BIRKBECK, T. H.; FEIST, S. W.; VERNER-JEFFREYS, D. W. Francisella infections in fish and shellfish. Journal of fish diseases, v. 34, n. 3, p. 173-187, 2011.
BUSH, A. O. et al. Parasitology meets ecology on its own terms: Margolis et al. revisited. The Journal of parasitology, p. 575583, 1997.

COLQUHOUN, D. J.; DUODU, S. Francisella infections in farmed and wild aquatic organisms. Vet Res, v. 42, n. 45, p. 1 15,2011 .

DEAK, E. et al. Comparison of the Vitek MS and Bruker Microflex LT MALDI-TOF MS platforms for routine identification of commonly isolated bacteria and yeast in the clinical microbiology laboratory. Diagnostic microbiology and infectious disease, v. 81, n. 1, p. 27-33, 2015.

DUODU, S. et al. The distribution of Francisella-like bacteria associated with coastal waters in Norway. Microbial ecology, v. 64, n. 2, p. 370-377, 2012. 
JAFAR, Q. A. et al. Molecular investigation of Streptococcus agalactiae isolates from environmental samples and fish specimens during a massive fish kill in Kuwait Bay. African Journal of Microbiology Research, v. 3, n. 1, p. 22-26, 2009.

LEAL, C. A.; TAVARES, G. C.; FIGUEIREDO, H. C. Outbreaks and genetic diversity of Francisella noatunensis subsp orientalis isolated from farm-raised Nile tilapia (Oreochromis niloticus) in Brazil. Genetics and Molecular Research, v. 13, n. 3, p. 5704-5712, 2014..

MARTINEZ, G.; HAREL, J.; GOTTSCHALK, M. Specific detection by PCR of Streptococcus agalactiae in milk. Canadian Journal of Veterinary Research, v. 65, n. 1, p. 68, 2001.

NGUYEN, V. V. et al. Francisella noatunensis subsp. orientalis, an emerging bacterial pathogen affecting cultured red tilapia (Oreochromis sp.) in Thailand. Aquaculture Research, p. 1-6, 2015

RYDZEWSKI, K. et al. Identification and characterization of episomal forms of integrative genomic islands in the genus Francisella. International Journal of Medical Microbiology, v. 305, n. 8 , p. $874-880,2015$.

SOTO, E.; ABRAMS, S. B.; REVAN, F.. Effects of temperature and salt concentration on Francisella noatunensis subsp. orientalis infections in Nile tilapia Oreochromis niloticus. Diseases of aquatic organisms, v. 101, n. 3, p. 217-223, 2012.

SOTO, E. et al. Development of a real-time PCR assay for identification and quantification of the fish pathogen Francisella noatunensis subsp. orientalis. Diseases of aquatic organisms, v. 89 , n. 3 , p. 199,2010 .

SOTO, E. et al. Biofilm formation of Francisella noatunensis subsp. orientalis. Veterinary microbiology, v. 181, n. 3, p. 313317, 2015.

SOTO, Esteban et al. Biofilm formation of Francisella noatunensis subsp. orientalis. Veterinary microbiology, v. 181, n. 3, p. 313-317, 2015.

VESTVIK, N. et al. Francisella noatunensis subsp. noatunensis replicates within Atlantic cod (Gadus morhua L.) leucocytes and inhibits respiratory burst activity. Fish \& shellfish immunology, v. 35 , n. 3 , p. $725-733,2013$. 